\title{
The influence of re-employment on quality of life and self-rated health, a longitudinal study among unemployed persons in the Netherlands
}

\author{
Bouwine E Carlier ${ }^{1 *}$, Merel Schuring ${ }^{1}$, Freek JB Lötters ${ }^{2}$, Bernhard Bakker ${ }^{3}$, Natacha Borgers ${ }^{3}$ and Alex Burdorf ${ }^{1}$
}

\begin{abstract}
Background: Unemployed persons have a poorer health compared with employed persons and unemployment may cause ill health. The aim of this study was to investigate the effect of re-employment on quality of life and health among unemployed persons on social benefits.

Methods: A prospective study with 18 months follow-up was conducted among unemployed persons $(n=4,308)$ in the Netherlands, receiving either unemployment benefits or social security benefits. Quality of life, self-rated health, and employment status were measured at baseline and every 6 months of follow up with questionnaires. Generalized estimating equations (GEE) modeling was performed to study the influence of re-employment on change in self-rated health and quality of life over time.

Results: In the study population $29 \%$ had a less than good quality of life and $17 \%$ had a poor self-rated health. Persons who started with paid employment during the follow-up period were more likely to improve towards a good quality of life (OR 1.76) and a good self-rated health (OR 2.88) compared with those persons who remained unemployed. Up to 6 months after re-employment, every month with paid employment, the likelihood of a good quality of life increased (OR 1.12).

Conclusions: Starting with paid employment improves quality of life and self-rated health. This suggests that labour force participation should be considered as an important measure to improve health of unemployed persons. Improving possibilities for unemployed persons to find paid employment will reduce socioeconomic inequalities in health.
\end{abstract}

Keywords: General health, Quality of life, Re-employment, Unemployment, Longitudinal study

\section{Background}

There is ample evidence for socioeconomic differences in health. Persons with a lower education, a lower occupational class, or a lower income die at younger age, and have, within their shorter lives, a higher prevalence of all kinds of health problems [1,2]. Unemployed persons are a specific socioeconomically disadvantaged group. The relationship between unemployment and poor health has been well established, as demonstrated by a higher prevalence of illness and disability [3-6] and a higher mortality among unemployed persons [7]. Two different

\footnotetext{
*Correspondence: b.carlier@erasmusmc.nl

'Department of Public Health, Erasmus MC, PO Box 2040, Rotterdam, CA 30000, The Netherlands

Full list of author information is available at the end of the article
}

mechanisms contribute to the poor health among unemployed persons. A poor health increases the probability of leaving the labour force and reduces the possibility of entering paid employment (selection hypothesis) [8-13] and unemployment may cause ill health (causation hypothesis) [13].

Unemployment is deleterious to physical health $[6,7,11,13]$ as well as to mental health [11,13-16]. The causation hypothesis also infers that entering paid employment is beneficial to health, but this mechanism is less well evaluated. Several studies have focused on reemployment and mental health. Various studies found that gaining paid employment improved mental health [16]. Another study found a reduction of distress for unemployed persons who found new jobs [14]. A follow-up

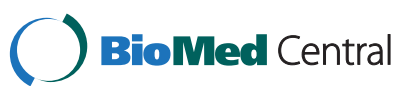


study in Norway among unemployed persons showed that re-employment reduced the chance of depression scores to $26 \%$ and the chance of anxiety scores to $13 \%$ compared to those who were still unemployed [17]. Thus, the positive influence of re-employment on mental health has been consistently demonstrated in several studies.

However, few studies have addressed other aspects of health, such as general health or health-related quality of life. Recently, a Dutch study among unemployed persons living in the City of Rotterdam found a positive effect of re-employment on general health, physical functioning, social functioning, vitality, mental health, bodily pain and role limitations due to emotional or physical problems, with effect sizes ranging from 0.11 to 0.66 [4]. Some studies have broadened the interest towards general quality of life, whereby quality of life is seen as a reflection of the way that persons perceive and react to their health status and all other aspects of their lives. It may be influenced substantially by psychological factors unrelated to health $[18,19]$. Quality of life generally decreases after unemployment $[5,20,21]$ although one recent study have shown that a considerable number of young adults considered they had attained a better quality of life since unemployment started [22].

Most longitudinal studies on quality of life have examined transitions from employment to unemployment, and there is less agreement about the influence of reemployment on quality of life [23,24]. A German study showed a large drop in quality of life after unemployment and an improvement after re-employment, but quality of life among re-employed persons remained below their original level many years after entering paid employment [23].

In conclusion, the impact of re-employment on mental health seems well-established. There is limited insight into the effect of re-employment on general health and quality of life. The objective of the present study was to determine the effect of re-employment on quality of life and self-rated health among unemployed persons on social benefits in the Netherlands.

\section{Methods}

\section{Design and study population}

A prospective study with 18 months follow-up was conducted among unemployed persons between 18 and 65 years receiving social benefits in the Netherlands. The data collection was part of an internal examination of the quality of the service at The Dutch Employment Centre to beneficiaries of unemployment benefits or social security benefits. Information was obtained on possible barriers for entering paid employment, including ill health, and the role of the social insurance agency in facilitating re-employment. Follow up questionnaires were sent to subjects who had indicated in the former questionnaire to be still unemployed. The Dutch Employment Centre generated a dataset of 70,121 persons, who were on social benefits for at least 6 months in 2006. From this dataset an age-stratified random sample was drawn of 20,847 persons on unemployment benefit (UB) or social security benefit (SSB). Four sequential questionnaires resulted in a 35\%, 59\%, 40\%, and $49 \%$ response. Persons with at least two complete questionnaires were included in the study. This resulted in a study sample of 4,308 persons of which 2,604 persons participated two times, 871 persons three times, and 833 persons four times. In order to find out whether the non-respondents differed from the respondents, a sample of 1000 non-respondents was approached with a brief questionnaire. More detailed information on this additional questionnaire is published elsewhere [25].

The two types of social benefits in the Netherlands are determined by a persons' history of paid work and the duration of the benefit. To be eligible for an unemployment benefit (UB) a Dutch worker must have had paid employment for at least 6 months prior to the benefit application. A social security benefits (SSB) is granted to all unemployed persons who do not have a recent history of paid employment of at least 6 months and do not have sufficient financial means to support themselves. The duration of UB depends on the total number of years worked, with a maximum of 5 years of this benefit. The duration of SSB is not limited in time. Long term unemployed persons and persons who have never worked will receive SSB. At baseline and every 6 months thereafter a questionnaire was sent to the home address, followed by a single reminder after four weeks. Persons who remained unemployed received consecutive questionnaires, whereas those entering paid employment had a maximum followup of 6 months after the transition into employment.

The study was conducted by the Inspection of Work \& Income of the Ministry of Social Affairs and Unemployment of the Netherlands (IWI) as part of their legal duty. According to Dutch law, approval by a Medical Ethical Committee is not required for a questionnaire survey among adults that does not influence a person's integrity and does not subject a person to specific procedures or rules of behaviour (information available at www.ccmo-online.nl). Participants were fully informed about the purpose and content of the study and the use of data for scientific research. They were informed that filling out the questionnaire would be regarded as provision of informed consent. Participation in the study was voluntary and could not interfere with getting benefits or re-employment activities since no information was transferred between IWI and employment services. IWI complied with the requirements set by the Data Protection Authority, gave permission for the current study, and provided anonymous data to Erasmus 
MC to carry out the current study. Access to the dataset can only be obtained after permission by IWI.

\section{Work status}

Re-employment was based on self-reports in the questionnaire on having entered paid employment in the past six months. Workers were asked whether they received additional Social Security or Unemployment Benefits. Those who did not receive any social benefit were defined as having paid employment. Persons were also asked the exact date of entering paid employment (see Additional file 1: IWI Questionnaire).

\section{Health and quality of life}

Quality of life was measured with the question 'How would you rate your life in general in the last six months?' on a ten point VAS scale [19]. Those reporting less than ' 6 ' were defined as having a poor quality of life. Self-rated health was measured by a slightly adjusted question, derived from SF36, "In general, how would you define your health in the last six months?" A five-point scale was used, ranging from 'very good, 'good', 'not good/not bad,' 'poor', to 'very poor' [26]. Those reporting a poor or very poor health were defined as having a poor health and others were classified as good health.

\section{Sociodemographic measures}

Sociodemographic variables, such as age, gender, education, ethnicity, having children and marital status were included in the questionnaire. Persons were divided into three groups according to their highest level of educational attainment. A low educational level was defined as no education, primary school or pre-highschool, an intermediate educational level as highschool or vocational education and a high educational level as higher vocational education or academic degree. Ethnicity was categorized as either native Dutch (both parents were born in the Netherlands) or non-native Dutch according to Statistics Netherlands (CBS 2010). Parenthood was defined as having children under 12 years living at home. Marital status was used to distinguish those persons married or living together from others.

\section{Data analyses}

The exact date of re-employment was unknown for 922 (49\%) respondents, for these persons, the re-employment duration was set at the population average of 3 months (imputation). A sensitivity analysis on subjects with complete information on exact month of entering paid employment $(n=905)$ showed similar results based on the observed and imputed values.

In order to study associations at baseline between sociodemographic factors, type of social benefit, with the health status, logistic regression analysis was used. In the first step of the analysis, univariate associations were evaluated. Subsequently, all variables in the univariate analyses with $\mathrm{p}<0.20$ were investigated in a multivariate analysis using a forward selection technique with significance level of $\mathrm{p}<0.05$.

Generalized estimating equations (GEE) modeling was performed with quality of life and self-rated health as dependent variables over time. Independent variables were employment status, duration of the employment, time, sex, age, education, ethnic background, parenthood, marital status and type of benefit. This analysis for repeated measurements considered demographic variables as time independent, whereas employment status, duration of the employment, health, and quality of life were time dependent variables. Quality of life and health were dichotomized in order to calculate odds ratios (OR) as measure of association. A simple correlation structure was chosen, assuming a uniform correlation for all possible pairs of variables within persons (exchangeable or compound symmetry). Quality of life and health at baseline were included as independent variables in the models, and, hence an OR above 1 reflects that among those with a transition from unemployment into paid employment health and quality of life improved compared with those without any transition.

In multivariate analyses, differential effects of reemployment on health and quality of life were calculated for gender, age, education, ethnicity and social benefit type. All analyses were performed with the statistical package SPSS-PASW 17 for Windows (Predictive Analytics SoftWare).

\section{Results}

Table 1 shows the sociodemographic characteristics of the study population. Among the unemployed persons $71 \%$ had a good quality of life, and $83 \%$ had a self-rated good health. Within the study population most persons (81\%) were on unemployment benefit whereas a minority (19\%) was on social security benefit. Persons on unemployment benefit reported more often a good health and a good quality of life than those on social security benefit, respectively $76 \%$ versus $48 \%(\mathrm{p}<0.05)$, and $86 \%$ versus $67 \%(p<0.05)$. Almost half of the unemployed persons $(43 \%)$ started with paid employment during the follow-up period.

The non-response analysis showed that participation was lower among persons with a lower education, persons on social security benefit, and persons under 35 years of age. An additional questionnaire among non-responders showed no differences in re-employment between responders and non-responders (details about the non-response analysis are published elsewhere [25].

Table 2 shows that younger $(<35$ years $)$ high educated persons were more likely to perceive their health as 
Table 1 Socio-demographic characteristics, quality of life, and self-rated health among unemployed persons with benefits at enrolment in the study $(n=4308)$

\begin{tabular}{ll}
\hline Variables & $\mathbf{n}(\%)$ \\
\hline Sex (Woman) & $2383(55.3)$ \\
Age & \\
$\quad$ 18-34 years & $848(19.7)$ \\
$\quad 35-44$ years & $1315(30.5)$ \\
$45-54$ years & $1206(28.0)$ \\
$\quad \geq 55$ years & $939(21.8)$ \\
Education level & \\
$\quad$ Low & $1780(41.3)$ \\
$\quad$ Intermediate & $1442(33.5)$ \\
$\quad$ High & $1086(25.2)$ \\
Ethnicity (native Dutch) & $3439(79.8)$ \\
No children <12 years & $3136(72.8)$ \\
Marital status (Living together) & $2951(68.5)$ \\
Social security benefit & $829(19.2)$ \\
Unemployment benefit & $3479(80.8)$ \\
Good quality of life & $3045(70.7)$ \\
Self-rated good health & $3562(82.7)$ \\
\hline
\end{tabular}

Table 2 Associations in multivariate logistic regression analyses between sociodemographic measures with selfrated good health and good quality of life among unemployed persons receiving benefits at enrolment in the study $(n=4308)$

\begin{tabular}{lll}
\hline Variables & $\begin{array}{l}\text { Self-rated good } \\
\text { health* OR (95\% CI) }\end{array}$ & $\begin{array}{l}\text { Quality of life* } \\
\text { OR (95\% CI) }\end{array}$ \\
\hline $\begin{array}{ll}\text { Sex (women) } \\
\text { Age }\end{array}$ & $0.87(0.73-1.04)$ & $1.07(0.92-1.23)$ \\
$\quad$ 18-34 years & 1 & 1 \\
$\quad$ 35-44 years & $0.77(0.61-0.98)$ & $0.89(0.73-1.08)$ \\
$\quad$ 45-54 years & $0.92(0.71-1.19)$ & $0.97(0.78-1.19)$ \\
$\quad$ 55-65 years & $0.83(0.63-1.08)$ & $1.72(1.35-2.18)$ \\
Education level & $1.20(0.99-1.45)$ & 1 \\
$\quad$ Low & $1.37(1.10-1.70)$ & $1.16(0.99-1.36)$ \\
$\quad$ Intermediate & $1.17(0.96-1.42)$ & $1.59(1.35-1.88)$ \\
$\quad$ High & $0.80(0.65-0.99)$ & $0.80(0.67-0.96)$ \\
Ethnicity (Native Dutch) & $1.50(1.26-1.79)$ & $1.67(1.43-1.94)$ \\
No children <12 years & & 1 \\
Marital status (living with \\
partner)
\end{tabular}

*Adjusted for sex, age, education, ethnic background, parenthood, marital status and benefit type.

$O R$, Odds ratio; $\mathrm{Cl}$, Confidence interval. good. In addition, persons who lived together with a partner or received unemployment benefits were also more likely to have a good health. A similar pattern was observed for good quality of life, with the exception of persons of older persons ( $>55$ years) who were more likely to report a good quality of life. There was a moderate correlation between self-rated health and quality of life (Spearman correlation $\mathrm{r}=0.42$ ).

Table 3 shows that persons who became re-employed were 2.88 times more likely to change from poor to good health compared with those who stayed unemployed (95\% CI 2.37-3.50). Up to a maximum of six months after re-employment, every month in paid employment after re-employment, the likelihood of improvement of health increased with 1.05 (95\% CI 0.93-1.18).

A similar effect of re-employment on quality of life was observed (Table 3). Re-employed persons were 1.76 times more likely to change from poor to good quality of life (95\% CI 1.54-2.02) compared with persons who continued to be unemployed. The duration of being reemployment was also positively associated with quality of life, increasing the likelihood of transition from poor to good quality of life with 1.12 (95\% CI 1.02-1.23) with each month.

Among re-employed persons, $60 \%$ improved, $40 \%$ did not change, and $4 \%$ worsened in self-rated health after the employment transition. Among persons who continued to be unemployed, 39\% improved, $61 \%$ did not change and $9 \%$ worsened in self-rated health. For quality of life similar patterns were observed. Among reemployed persons $37 \%$ improved, $63 \%$ did not change and $8 \%$ worsened in quality of life, whereas persons who continued to be unemployed $23 \%$ improved, $77 \%$ did not change and $8 \%$ improved.

The beneficial effect of re-employment on health was more profound among men (OR 3.65 95\% CI 2.60-5.12) than among women (OR $2.1095 \%$ CI 1.62-2.71) (Table 4). The positive effect of re-employment on self-rated health and quality of life decreased with increasing age. In addition, among native Dutch persons (OR 4.01 95\% CI 3.00-5.14) the increase in health was larger compared to non-native Dutch persons (OR 2.22 95\% CI 1.52-3.22). Educational level of type of benefit did not influence the effect of re-employment on health or quality of life.

\section{Discussion}

Re-employment had a positive effect on self-rated health and quality of life. Persons who became re-employed were almost three times more likely to improve from poor to good health and 1.76 times more likely to improve from a poor to good quality of life after entering paid employment, compared with those who continued to be unemployed. For every month in paid employment 
Table 3 The effect of re-employment on the probability to improve from poor to good quality of life and good self-rated health among unemployed persons during 18 months follow-up $(n=4308)$

\begin{tabular}{|c|c|c|c|c|}
\hline & \multicolumn{2}{|c|}{ Good self-rated health } & \multicolumn{2}{|l|}{ Quality of life } \\
\hline & Unadjusted model* & Adjusted model ${ }^{* *}$ & Unadjusted model* & Adjusted model** \\
\hline & OR (95\% Cl) & OR (95\% Cl) & OR (95\% Cl) & OR (95\% Cl) \\
\hline Re-employment transition & $3.14(2.60-3.81)$ & $2.88(2.37-3.50)$ & $2.21(2.07-2.36)$ & $1.76(1.54-2.02)$ \\
\hline Time re-employed (months) & $1.06(0.94-1.19)$ & $1.05(0.93-1.18)$ & $1.12(1.03-1.23)$ & $1.12(1.02-1.23)$ \\
\hline
\end{tabular}

*Adjusted for time. ${ }^{* *}$ Adjusted for time, sex, age, education, ethnic background, parenthood, marital status, and type of benefit. OR, Odds ratio; $\mathrm{Cl}$, Confidence interval.

after re-employment, the likelihood of changing towards a good quality of life increased with 1.12 .

The longitudinal design with up to four measurements in one and a half year gives more insight into the change of health before and after entering paid employment. Persons only participated in the study one more time after re-employment, so the maximum follow-up after the employment transition was six months. Previous studies showed the largest change in health in the first months after re-employment transition $[4,17]$.

Table 4 Differential effects of re-employment on the probability to improve from poor to good quality of life and self-rated health among unemployed persons during 18 months follow-up for gender, age, and type of benefit $(n=4308)$

\begin{tabular}{|c|c|c|}
\hline & $\begin{array}{l}\text { Good self-rated } \\
\text { health adjusted } \\
\text { model** OR } \\
(95 \% \mathrm{Cl})\end{array}$ & $\begin{array}{l}\text { Good quality } \\
\text { of life adjusted } \\
\text { model** OR } \\
(95 \% \mathrm{Cl})\end{array}$ \\
\hline Total population & $2.88(2.37-3.50)$ & $1.76(1.54-2.02)$ \\
\hline \multicolumn{3}{|l|}{ Gender } \\
\hline Men $\times$ Unemployed & 1 & 1 \\
\hline Men $\times$ Re-employed & $3.65(2.60-5.12)$ & $1.48(1.22-1.79)$ \\
\hline Women $\times$ Unemployed & $0.82(0.70-0.96)$ & $1.17(1.03-1.33)$ \\
\hline Women $\times$ Re-employed & $2.10(1.62-2.71)$ & $2.40(1.97-2.94)$ \\
\hline \multicolumn{3}{|l|}{ Age } \\
\hline 18-34 years $\times$ Unemployed & 1 & 1 \\
\hline 18-34 years $\times$ Re-employed & $3.07(1.98-4.76)$ & $1.96(1.47(2.61)$ \\
\hline 35-44 years $\times$ Unemployed & $0.72(0.58-0.90)$ & $0.87(0.72-1.04)$ \\
\hline 35-44 years $\times$ Re-employed & $2.49(1.71-3.63)$ & $1.6891 .30-2.16)$ \\
\hline 45-54 years $\times$ Un-employed & $0.83(0.65-1.06)$ & $0.93(0.77-1.12)$ \\
\hline $45-54$ years $\times$ Re-employed & $2.17(1.45-3.22)$ & $1.66(1.26-2.18)$ \\
\hline $55-65$ years $\times$ Un-employed & $0.98(0.76-1.27)$ & $1.81(1.47-2.23)$ \\
\hline 55-65 years $\times$ Re-employed & $2.07(1.24-3.46)$ & $2.00(1.37-2.91)$ \\
\hline \multicolumn{3}{|l|}{ Ethnicity } \\
\hline Un-employed $\times$ Non-native Dutch & 1 & 1 \\
\hline Employed $\times$ Non-native Dutch & $2.22(1.52-3.22)$ & $1.44(1.11-1.88)$ \\
\hline Un-employed $\times$ Native Dutch & $1.28(1.06-1.50)$ & $1.68(1.46-1.93)$ \\
\hline Employed $\times$ Native Dutch & $4.01(3.00-5.14)$ & $3.15(2.60-3.82)$ \\
\hline
\end{tabular}

**Adjusted for time, sex, age, education, ethnic background, parenthood, marital status, and type of benefit. OR, Odds ratio; $\mathrm{Cl}$, Confidence interval.
Therefore, this study gives important information on the effects of re-employment on health and quality of life.

The response of the four sequential waves varied between $35 \%$ and $59 \%$. Non-participation and loss-to follow up were more frequent among younger, low educated, non-native persons and persons on social security benefits. The current study showed that the effect of reemployment on health was not influenced by educational level or type of benefit. Re-employment resulted in less health benefits among persons with a non-Dutch origin and more health benefits among younger persons. Therefore, the effect of re-employment on health may be biased by selective loss to follow-up.

The monthly improvement of quality of life after reemployment was higher (OR 1.12, 95\% CI 1.02-1.23] than the improvement of self-rated health (OR 1.06). The larger improvement of quality of life is likely to be explained by differences in scale size and precision of the two measures (10-point scale compared to 5-point Likert-scale). The proportion of persons reporting poor health might be too small to improve significantly. A more sensitive instrument measuring general health would have showed the positive health effect of the duration of re-employment more clearly. However, a trend in improvement of health and quality of life is demonstrated.

This study showed a positive association between reemployment and a change of self-rated health after controlling for several important determinants of health. Due to practical and ethical reasons, the effect of reemployment on self-rated health cannot be studied in a randomized controlled trial. Nevertheless, in this study we observed a stable proportion of persons experiencing poor health in the group of prolonged unemployed persons $(61 \%)$ and this stability is in congruence with earlier studies [13]. Repeated measurements analyses showed that among re-employed persons $60 \%$ improved in selfrated health. The improvement of health among reemployed persons compared to the stable trend of health among persons who continued to be unemployed provides evidence for a causal relation between re-employment and changes in health.

The positive change in self-rated health as a consequence of re-employment transition is in accordance with 
findings from previous studies. Recent studies found that re-employment had a positive effect on physical health [4], limiting illness [5] and mental health $[4,8,16,27]$. Other studies showed the positive effect of re-employment on psychological symptoms [7], well-being $[11,14]$ and life satisfaction [23]. Only two studies addressed physical health, a Dutch study showed that re-employment positively influenced mental health as well as physical health in a short time window [4] and a Norwegian longitudinal study reported a positive effect of re-employment on somatic symptoms [17].

The current study shows that starting with paid employment positively influences health and quality of life. However, there are differences between native and nonnative Dutch person in the effect of re-employment on health and quality of life. Persons from minority ethnic groups may be disadvantaged in terms of pay, working conditions and job status, all factors explaining the relation between employment and health [28]. The positive health effect of becoming employed may be limited to certain employment conditions, for instance the psychosocial quality of the work [29], the number of hours worked and the type of contract, flexible versus permanent $[27,30]$. In addition, among ethnic minorities in the Netherlands, flex-work is on average about twice as high as among Dutch workers [31]. However, although the non-native re-employed persons show a smaller increase in health compared to the native Dutch re-employed persons, they are still better of than their unemployed counterparts. This is also found by Grun et al. [24], who suggests that job quality only matters to some extent, since there is evidence that persons in poor quality employment are still better off, report a higher life satisfaction, than those who remain unemployed.

The current study showed that the effect of reemployment on self-rated health and quality of life decreased with an increase in age. Several studies have found that the negative effect of unemployment on health is especially large for the younger age groups [32]. Older workers who are approaching retirement may be able to cope better with unemployment compared with the younger workers who will be staying longer in the labour force. Therefore, especially among younger persons the negative effect of unemployment on health can be reversed by reemployment.

\section{Conclusions}

This study shows that persons who became re-employed were three times more likely to have a good health status after the transition into paid employment. These results suggest re-employment has a relatively large effect on general health. Unemployed persons are a specific socioeconomically disadvantaged group with a relatively poor health. Re-employment is an important stimulus for improving health and reducing socioeconomic inequalities in health. Hence, labour force participation should be on the health agendas of many national governments [33-35]. Improving possibilities for unemployed persons to find paid employment will have a positive effect on public health.

\section{Additional file}

Additional file 1: IWI Questionnaire.

\section{Abbreviations}

UB: Unemployment benefit; SSB: Social security benefit; GEE: Generalized estimating equations.

\section{Competing interests}

All authors declare that they have no competing interests.

\section{Authors' contribution}

FJBL and BB are responsible for the data collection. BEC carried out the analysis, interpreted and reported the study results and drafted the manuscript. FJBL, BB and NB provided content expertise. MS and AB conceived the study, provided content expertise, and critically edited all versions. All authors read and approved the final manuscript.

\section{Author details}

'Department of Public Health, Erasmus MC, PO Box 2040, Rotterdam, CA 30000, The Netherlands. ${ }^{2}$ Institute of Health Policy \& Management, Erasmus University Rotterdam, Rotterdam, The Netherlands. ${ }^{3}$ Inspection Service for Work and Income, Ministry of Social Affairs and Employment, The Hague, The Netherlands.

Received: 3 December 2012 Accepted: 8 May 2013

Published: 24 May 2013

\section{References}

1. Mackenbach JP, Stirbu I, Roskam AJ, Schaap MM, Menvielle G, Leinsalu M, Kunst AE: Socioeconomic inequalities in health in 22 European countries. N Engl J Med 2008, 358:2468-2481.

2. Mackenbach JP: Health. Inequalities: Europe in Profile. An independent, expert report commissioned by, and published under the auspices of, the UK Presidency of the EU; 2005.

3. Weich S, Lewis G: Poverty, unemployment, and common mental disorders: population based cohort study. BMJ 1998, 317:115-119.

4. Schuring M, Mackenbach J, Voorham T, Burdorf A: The effect of re-employment on perceived health. J Epidemiol Community Health 2011, 65:639-644.

5. Bartley M, Sacker A, Clarke P: Employment status, employment conditions, and limiting illness: prospective evidence from the British household panel survey 1991-2001. J Epidemiol Community Health 2004, 58:501-506.

6. Mathers CD, Schofield DJ: The health consequences of unemployment: the evidence. Med J Aust 1998, 168:178-182.

7. Roelfs DJ, Shor E, Davidson KW, Schwartz JE: Losing life and livelihood: a systematic review and meta-analysis of unemployment and all-cause mortality. Soc Sci Med 2011, 72:840-854.

8. Thomas C, Benzeval M, Stansfeld SA: Employment transitions and mental health: an analysis from the British household panel survey. J Epidemiol Community Health 2005, 59:243-249.

9. Van den Berg T, Schuring M, Avendano M, Mackenbach J, Burdorf A: The impact of ill health on exit from paid employment in Europe among older workers. Occup Environ Med 2010, 67:845-852.

10. Schuring $M$, Burdorf $L$, Kunst $A$, Mackenbach J: The effects of ill health on entering and maintaining paid employment: evidence in european countries. J Epidemiol Community Health 2007, 61:597-604.

11. Wanberg CR: The individual experience of unemployment. Annu Rev Psychol 2012, 63:369-396. 
12. Claussen B, Bjorndal A, Hjort PF: Health and re-employment in a two year follow up of long term unemployed. J Epidemiol Community Health 1993, 47:14-18.

13. Janlert U: Unemployment as a disease and diseases of the unemployed. Scand J Work Environ Health 1997, 23:79-83.

14. Paul Kl, Moser K: Unemployment impairs mental health: Meta-analyses. J Vocat Behav 2009, 74:264-282.

15. Price RH, Choi JN, Vinokur AD: Links in the chain of adversity following job loss: how financial strain and loss of personal control lead to depression, impaired functioning, and poor health. J Occup Health Psychol 2002, 7:302-312.

16. Murphy GC, Athanasou JA: The effect of unemployment on mental health. J Occup Organ Psychol 1999, 72:83-99.

17. Claussen B: Health and re-employment in a five-year follow-up of long-term unemployed. Scand J Publ Health 1999, 27:94-100.

18. Diener E, Emmons RA, Larsen RJ, Griffin S: The satisfaction with life scale. J Pers Assess 1985, 49:71-75.

19. Muldoon MF, Barger SD, Flory JD, Manuck SB: What are quality of life measurements measuring? BMJ 1998, 316:542.

20. Blanc P: Why quality of life should matter to occupational health researchers. Occup Environ Med 2004, 61:571.

21. Brereton F, Clinch JP, Ferreira S: Employment and life-satisfaction: insights from ireland. Economic Soc Rev 2008, 39:207-234.

22. Axelsson L, Andersson I, Edén L, Ejlertsson G: Inequalities of quality of life in unemployed young adults: a population-based questionnaire study. Int J Equity Health 2007, 6(1):1.

23. Lucas RE, Clark AE, Georgellis Y, Diener ED: Unemployment alters the set point for life satisfaction. Psychol Sci 2004, 15:8-13.

24. Grün C, Hauser W, Rhein T: Is Any Job Better than No Job? Life Satisfaction and Re-employment. J Lab Res 2010, 31:285-306.

25. Lötters F, Carlier B, Bakker B, Borgers N, Schuring M, Burdorf A: The influence of perceived health on labour participation among long term unemployed. J Occup Rehabil 2012, 11:1-9.

26. Ware JE Jr, Sherbourne CD: The MOS, 36-item short-form health survey (SF-36). I. Conceptual framework and item selection. Med Care 1992, 30:473-483.

27. Reine I, Novo M, Hammarström A: Does transition from an unstable labour market position to permanent employment protect mental health? Results from a 14-year follow-up of school-leavers. BMC Publ Health 2008, 8:159

28. Cooper $\mathrm{H}$ : Investigating socio-economic explanations for gender and ethnic inequalities in health. Soc Sci Med 2002, 54(5):693-706.

29. Butterworth P, Leach L, Strazdins L, Olesen SC, Rodgers B, Broom DH: The psychosocial quality of work determines whether employment has benefits for mental health: results from a longitudinal national household panel survey. Occup Environ Med 2011, 68:806-812.

30. Strandh M: Different exit routes from unemployment and their impact on mental well-being: the role of the economic situation and the predictability of the life course. Work Employment Soc 2000, 14(3):459-479.

31. Veenman J, Dagevos JM: [Ethnic minorities and labour market flexibilisation] Allochtonen en de flexibilisering van de arbeidsmarkt. Tijdschrift. Soc Wetenschappen 1999, 42(2):106-121.

32. Bender KA, Economou A, Theodossiou I: The permanent and temporary impact of the unemployment rate on Mortality. The European Experience. International Labour Review: 2012.

33. Baume F: The new public health: an Australian perspective. South Melborne: Oxford University Press; 1998

34. Ågren G: folkhälsan Sif. Sweden's new public health policy: National public health objectives for Sweden. Sweden: Swedish National Institute of Public Health; 2003.

35. Black CM: Working for a healthier tomorrow: Dame Carol Black's review of the health of Britain's working age population. London: TSO; 2008.

doi:10.1186/1471-2458-13-503

Cite this article as: Carlier et al:: The influence of re-employment on quality of life and self-rated health, a longitudinal study among unemployed persons in the Netherlands. BMC Public Health 2013 13:503.

\section{Submit your next manuscript to BioMed Central and take full advantage of:}

- Convenient online submission

- Thorough peer review

- No space constraints or color figure charges

- Immediate publication on acceptance

- Inclusion in PubMed, CAS, Scopus and Google Scholar

- Research which is freely available for redistribution

Submit your manuscript at www.biomedcentral.com/submit 